\title{
Massive energy storage systems enable secure electricity supply from renewables
}

\author{
Alan J. SANGSTER ${ }^{1}$
}

\begin{abstract}
Climate change is mainly attributed to the burning of fossil fuels. To solve the problem, current inhabitants have to dispense with fossil fuels as a source of power. It has been demonstrated that this can be secured before 2050 by transitioning to renewable sources of energy. Massive energy storage (MES) incorporated into long distance high voltage direct current (HVDC) transmission systems is the key technology for the transition. This paper describes the current state-of-the-art in electricity grid configurations. It demonstrates how MES, and other back-up local electricity storage schemes represent a natural way of buffering electricity consumers from the intermittency of inherent in the primary renewable systems. Consequently, it can solve the base-load issues and facilitate a global transition to $100 \%$ renewable energy sources over the next fifteen to twenty years.
\end{abstract}

Keywords Electricity grid, Energy storage, Pumpedhydro, Lagoon storage, Hydraulic piston, Climate change

\section{Introduction}

By five years from now, in 2020, a rational assessment of the climate science suggests that, to avoid dangerous levels of global warming, the burning of fossil fuels needs to be heavily proscribed, and mankind should be directing

CrossCheck date: 27 June 2016

Received: 6 July 2015/Accepted: 27 June 2016/Published online: 16 August 2016

(c) The Author(s) 2016. This article is published with open access at Springerlink.com

$\triangle$ Alan J. SANGSTER

a.j.sangster@hw.ac.uk

1 School of Engineering and Physical Sciences, Heriot-Watt University, Riccarton Campus, Edinburgh EH14 4AS, UK maximum effort towards creating renewable energy power systems. The early transition to renewable energy sources is necessary to improve our 'green' credentials and enable the abandonment of fossil fuels, without sacrificing our advanced technological societies.

Developing evidence suggests that planning for these renewable energy delivery systems will have to be predicated on operation at the continental level. For example, in Europe, a viable direct current (DC) super-grid, mooted in several recent reports, would connect geothermal power stations in central Europe, solar power stations in southern Europe, wind farms in Western Europe, wave/tidal systems off Scotland, Norway and Portugal, hydroelectric stations in Northern Europe, and nuclear power stations in France. This system would be backed up by massive storage facilities based on compressed gas and hot water thermal storage using cathedral sized underground caverns, on massive battery farms, and on pumped storage employing conventional high altitude reservoirs, and artificial lagoons constructed in shallow sheltered bays, as planned for the coastal waters off Denmark. Continuity of supply from diverse intermittent sources dictates that a super-grid, which is geographically extensive and employs a multiplicity of sources, will assist in this goal.

In a future world weaned off fossil fuels, the power to drive all sectors of our modern economies will have to be delivered through the agency of electricity - except perhaps for a limited number of licensed users of fossil fuels and some users of biofuels. Consequently, nations will have to unite to expand their electricity grids to continental coverage [1] and to enhance efficiency by large scale adoption of 'smart' technology [2]. The European Commission is edging in this direction. Unfortunately doubt continues to be expressed on the practices of the current electrical power industry, that without flexible 'base load', 
provided today by fossil fuel power stations, a geographically extensive grid based electricity supply system capable of delivering dependable power is incompatible with renewables, particularly wind, wave and solar power. While this attitude prevails, progress towards the realisation of a renewables based electricity grid will be slow.

The source of the above assertion lies in the need, in our traditional AC grid system, to actively intervene to balance supply and demand, otherwise frequency stability is degraded. In fact, the grid frequency is a system-wide measure of overall power imbalance. For example, if demand becomes too high, thereby drawing excess current through any given electrical power generator, an unavoidable Lorentz braking force is initiated resulting in a decrease in its rotational speed. If the generator is operated in frequency-response mode, whereby it normally runs at reduced output, a buffer of spare capacity is available. In this case the generator can continually alter the power it delivers to the grid on a second-to-second basis using what is termed droop speed control - a feedback signal to the turbine directing it to boost its power. If demand exceeds this level of control it becomes necessary to power up 'idle' additional turbine/generator sets. This mode of operation is effective for the power utilities particularly when accurate predictions of the demand profile are available. Needless to say this 'balancing act' is deemed to be severely compromised by the introduction of 'inflexible' and 'intermittent' renewable sources.

A schematic of traditional transmission and distribution grid is presented in Fig. 1. The blue connections represent $200 \mathrm{kV} \mathrm{AC}$ or HVDC; orange connections represent $100 \mathrm{kV}$ transmission grid; and green connections represent $50 \mathrm{kV}$ distribution grid. It is typically divided into three

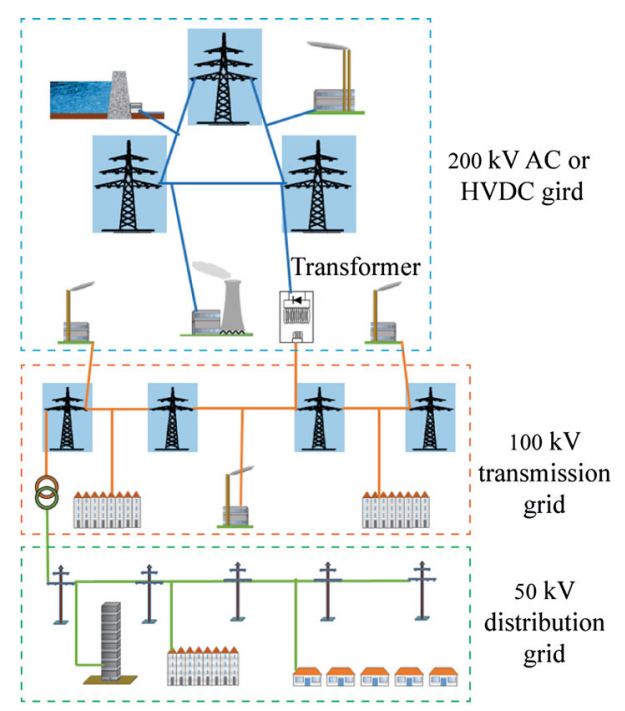

Fig. 1 Schematic of a conventional fossil fuel powered electricity grid as currently operating in 2015 operational segments as follows. Firstly, the very high voltage section, linked by blue 'transmission lines'. In practice, the system comprises a network of transmission lines with 'built-in' redundancies. This long range section is, today, mostly $\mathrm{AC}$ based but can employ some high voltage DC (HVDC) with voltages in the $250 \sim 275 \mathrm{kV}$ range. The electrical power to this section of the grid is conventionally provided by coal power stations (of 600 MW capacity - top right symbol), nuclear power stations (500 1500 MW -central symbol) and hydroelectric systems (200 MW - top left symbol).

Over shorter distances, the grid voltage is generally transformed down to about $100 \mathrm{kV}$ as indicated by the transformer symbol between the blue and orange transmission line representations. At this voltage level, power is fed onto the grid, typically from gas power plants (150 MW - central symbol in $100 \mathrm{kV}$ box), and industrial plants (50 MW), while simultaneously power is distributed to factories and other high voltage consumers. Primary distribution is normally carried out at about $50 \mathrm{kV}$. In this segment, the grid predominantly provides electrical power to consumers, such as factories, administrative offices, hospitals, schools and housing estates. Historically, on conventionally operated systems, generators have seldom formed part of the distribution grid.

The favoured electrical power source on the conventional grid is the synchronous generator. This is tricky when, for any given machine on the grid, both parameters are influenced by any imbalance between the machine load and the power supplied to the input shaft. Hence the need to predictively balance supply and demand. In simple terms smart monitoring provides signals to a local governor that regulates the turbine driving torque by controlling the steam supply to it, and hence the speed of each generator is maintained. Generation and consumption must be balanced across the entire grid, because energy is consumed almost at the instant it is produced. Energy storage is largely absent.

In general electrical engineering practice outside of the power supply industry, this deliberate need for predictive balancing of supply and demand is actually not an issue. For example, any standalone complex electronic device, such a mobile phone, laptop computer or electric car, is a small but self-contained power system. It exhibits varying power demand from a multiplicity of electrical circuits and components which are influenced by changing operational modes, while the electrical supply comes from an energy storage device (usually a battery). Obviously, but significantly, this energy source delivers power only when it is needed. Thus supply and demand are automatically balanced. If the battery is rechargeable, which it usually is, then balanced demand/supply is maintained as long as the battery contains sufficient charge. Importantly, it does not matter how erratic or intermittent the charging process is as 
long as on average over a defined time period, the charging power supplied to the battery is equal to or greater than the power demanded over the same interval, by the electrical circuits of the device in question.

The inference of the above routine electronic circuit behaviour is that an electrical power supply system, at the national grid level, should function adequately with intermittent renewables acting as the primary power sources, provided the supply side is buffered from the demand side by massive energy storage (MES) plants, such as pumped hydroelectric schemes. The grid has to carry AC power, for transmission and distribution reasons, the buffering storage plants will be required to drive turbine/generator sets little different from those currently employed in today's power stations. Demand management will very likely parallel current practice. A few, but far too few, of these storage facilities are finding a place in global grid systems. There are many other massive storage technologies which could be implemented for example the Nordhavn 'green island' storage scheme near Copenhagen, but unfortunately effective development is almost non-existent at the present time.

\section{Literature review - massive energy storage}

A power transmission grid is generally a routine electrical circuit except that it entails carrying power generated at geographically separated locations over long distances to customers or users (loads) at other geographical locations. In addition to this geographical element, a further difference from a conventional DC or very low frequency AC circuit is a multiplicity of generators and loads (Fig. 1). Conventional grid systems operate satisfactorily provided the network exhibits spare capacity, both in terms of redundant transmission line routes, to facilitate the bypassing of damaged lines, and in terms of power generators to ensure a balance between supply and demand can be maintained in all circumstances. The latter, arguably, has been made easy over the past century by the abundance of fossil fuels driving the development of affordable and reliable thermal power stations. These until very recently have represented the core of the electricity grid system. Unfortunately, the effluent from these fossil fuel power stations is harmful to the planetary eco-system, because of the warming effect of carbon dioxide in the atmosphere [3-5]. Carbon capture [6] could solve the problem, but technological implementation remains much too far into the future to meaningfully address the climate change crisis.

\subsection{Distribution level storage}

The currently favoured solution $[1,7,8]$ envisages all of our power being supplied from renewable sources, with some backup from already existing 'clean' nuclear power stations in the form of integral fast reactors (IFR's), plus any which can be brought 'on stream' by 2020 . However, in order to achieve abandonment of fossil fuels by 2030, as dictated by the climate science, the major drive by mankind has to be towards securing clean energy from renewables. The major 'stumbling block' for this strategy is intermittency, particularly from wind, solar and wave sources [9]. It is usually claimed that security and quality of supply on a grid which accommodates renewable sources of electricity requires 'base load' generating stations fueled by coal, oil or natural gas to smooth out power fluctuations.

Actually, the state-of-the-art literature suggests otherwise. On-going research and development is beginning to demonstrate that grid fluctuations can be corrected by alternatively incorporating MES into the system [10-13]. References [10-13] provide comprehensive evaluations of viable storage technologies, which represent potentially good candidates for incorporation into electrical grid systems. These range from pumped-hydro, compressed air, flywheels, super-conducting coils, hydrogen (in fuel cells) to chemical techniques including batteries. The relative power and storage capabilities of the various storage methods are usefully emphasized in [10] and [13]. On the other hand while the Teleke paper [11] is also directed at enumerating and describing all of the major storage techniques, it additionally provides a grid case study. The example presented involves the addition to a conventional grid system of a self-contained branch accommodating wind and solar power sources, but backed-up by a battery energy storage system (BESS). The simulation demonstrates that there is a clear benefit from incorporating energy storage into an electrical power system, with the model showing that imposed generator fluctuations are virtually eliminated from the supplied grid voltage. These results are supported in a paper from Rodrigues et al. [14] which addresses electrical power distribution systems located on compact island real estates. The growing introduction of storage units into the distribution grid is discussed by Chen [15], where the additional element is referred to as a distributed energy resource (DER). This paper draws attention to the probability that storage requirements for 'low voltage' distribution functions will differ from those required to support transmission as is suggested in Fig. 2.

A full range of electrical storage systems, calibrated on a power output in megawatts (MW) versus energy stored in Megawatt-hours (MWh) basis, is presented in Fig. 3, in which FBES stands for flow-battery energy storage; SLHS stands for sea level hydro storage; CAES stands for compressed air energy storage; PHES stands for pumped hydro energy storage; BES stands for battery energy storage; SCES stands for super capacitor energy storage; FES 


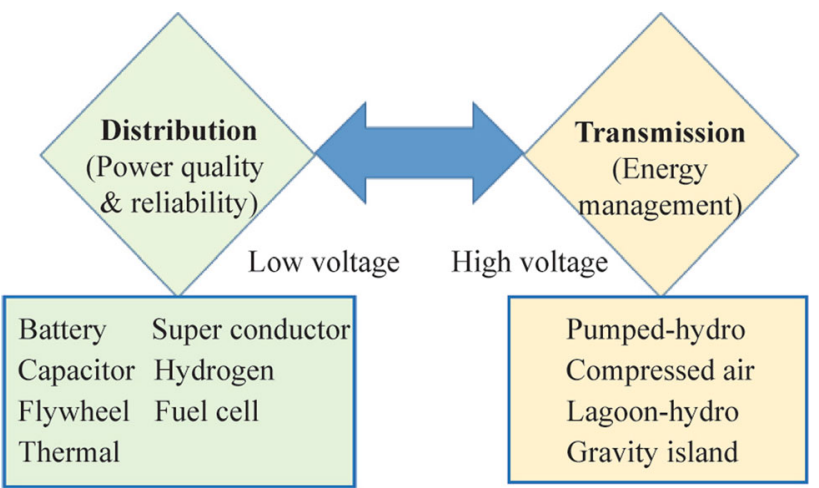

Fig. 2 Energy storage allocation in accordance with operating voltage

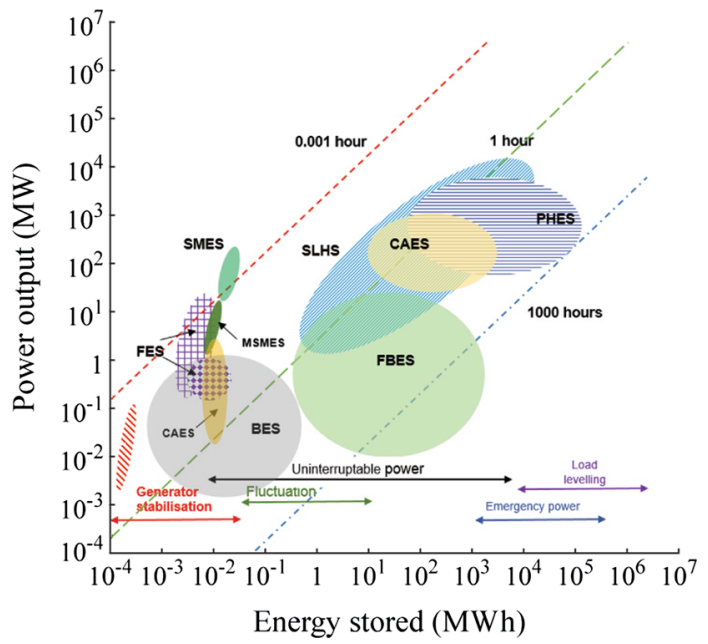

Fig. 3 Power/energy capabilities of a range of promising electrical storage systems [23]

stands for flywheel energy storage; and SMES stands for superconducting magnet energy storage) The geologically based storage methods (pumped-hydro and compressed air) exhibit the potential to provide the real MES levels, in the $1 \mathrm{GWh}$ to $100 \mathrm{GWh}$ range, suitable for load levelling and emergency back-up in high voltage transmission systems. On the other hand, manufactured storage techniques such as in batteries, flywheels, superconducting coils and super capacitors are evidently of limited storage capacity, but have the advantage of providing rapid charging and discharging cycles. These systems are likely to be best used in distribution, for stabilising generators and smoothing relatively short term grid fluctuations. Flow batteries [10] represent an intermediate capacity energy storage technique and seem likely to fill the role of providing uninterruptible electrical power in scenarios, such as hospitals, where reliability of supply is critical.

The financial implications of adopting storage technology, on a very large scale, have been examined in some

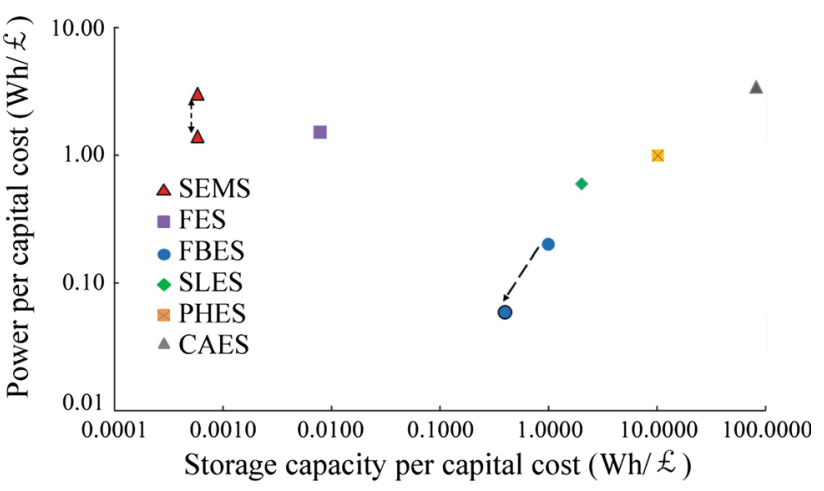

Fig. 4 Power/energy storage capability of some storage systems with costs factored in [16]

detail in the literature, although the main contributions to cost are evidently difficult to identify and quantify thus making definitive conclusions elusive. Nevertheless, Kondoh [16] has made a laudable attempt to do so which involves expressing the axes quantities in Fig. 3 on a per unit cost basis as shown in Fig. 4. The result is that the major storage methods remain located on the modified graph in positions not too dissimilar to their locations in Fig. 3. This is because pumped-hydro and compressed air can be developed economically, if installed in already existing and favourable geological sites, and so graphically remain positioned to the top right of Fig. 4 in 'costed' form. On the other hand, magnetic field storage using expensive superconductors, flywheels and batteries all require high capital injections to achieve operational status, and hence continue to appear to the left of the costed figure because for these systems energy stored per unit cost tends to be low. Note that for FBES the position on Fig. 4 becomes less favourable if lifetime considerations are addressed (see dashed down arrow).

\subsection{Transmission level storage}

Figure 3 shows that the MES methods require the assistance of nature with conducive geological and geographical sites. Unfortunately, pumped-hydro energy storage based on high altitude reservoirs, and compressed air storage based on geologically formed air tight underground caverns, are a rather limited resource, with all of the best sites already largely commandeered. Yet in any future electricity generation system, based on renewable sources, reliability of supply will require many more MES plants than are currently in existence.

\subsubsection{Lagoon hydraulic storage}

A potential solution to this problem lies with lagoon storage systems, which are essentially reworkings of tidal 
barrage renewable energy schemes. The concept has been described in [17] and [18]. The operational principles behind this technology advance are illustrated in Fig. 5 . The lagoon is envisaged as being dredged to below sea level in a suitable bay and enclosed by an island atoll surrounded by sea water. At times when electricity demand is less than supply, in the neighbouring renewables powered grid, power from the grid is used to drive turbine/ pumps which empty the lagoon (Fig. 5a). On the other hand, when the scenario changes to one where there is more demand than supply the lagoon is allowed to fill from the sea. The complex then becomes a generating station as the inflowing sea water drives the turbines in generator mode (Fig. 5b).

In order to gauge the technical feasibility of lagoon based gravitational energy storage, at a massive scale, at sea level, it is necessary to establish some basic relationships between energy stored, power and artificial lagoon extent. This can be done quite readily [19] for a regularly shaped lagoon of constant cross-sectional area $\left(A\right.$ in $\left.\mathrm{m}^{2}\right)$ and height $h(\mathrm{~m})$ as indicated in Fig. 5. The potential energy stored in the basin for a water layer of depth $d h$ at height $h$ is then:

$d E_{P E}=\rho A h g d h$

where $g$ is the gravitational acceleration $\left(9.81 \mathrm{~m} / \mathrm{s}^{2}\right)$. Thus the total gravitational energy contained in a full basin of water is just:

$E_{P E}=\int_{0}^{h} d E_{P E}=\rho A g \int_{0}^{h} h d h=\frac{\rho A g h^{2}}{2}$

where $\rho\left(\mathrm{kg} / \mathrm{m}^{3}\right)$ is the density of water. The power available in the out flowing water at the foot of the lagoon

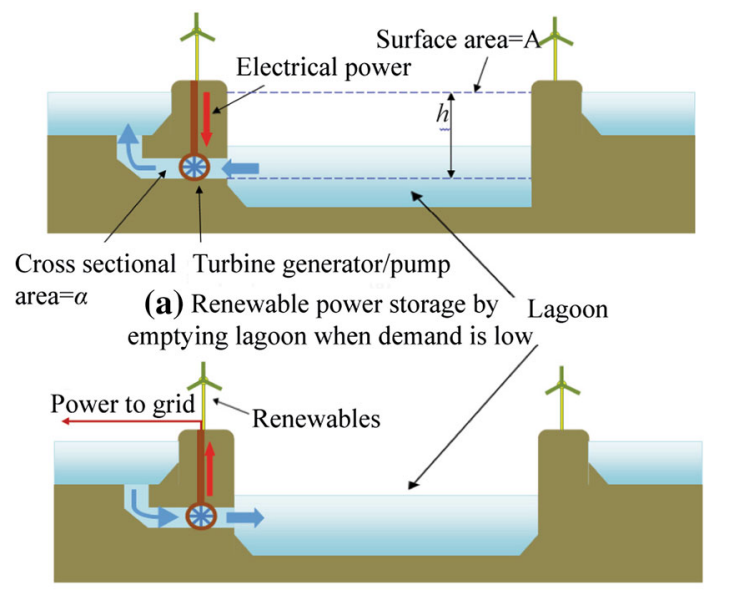

(b) Electrical power supply when demand is high by releasing sea water into the lagoon

Fig. 5 Lagoon power storage system can be estimated from the basic hydraulic relationship which states that the volume of water discharged $\left(V_{\text {out }}\right)$ through the turbine passage is equated to the change in lagoon water volume, which is negative for outflow and positive for inflow. Therefore:

$-A d h=V_{\text {out }} d t$

At a typical lagoon outlet as suggested in Fig. 5, it is appropriate [19] to apply a discharge coefficient $C_{D} \approx 0.75$. The discharge volume can then be estimated from:

$V_{\text {out }}=C_{D} a(2 g h)^{\frac{1}{2}}$

So the discharge time for a change in lagoon height of $d h$ is therefore

$d t=-\frac{A}{C_{D} a(2 g h)^{\frac{1}{2}}} d h$

and the total discharge time $T_{h}$ to lower the lagoon surface from $h$ to zero is, by integration:

$T_{h}=\int_{h}^{0} d t=-\frac{A}{C_{D} a(2 g)^{\frac{1}{2}}} \int_{h}^{0} h^{-\frac{1}{2}} d h$

Hence

$T_{h}=\frac{2 A h^{\frac{1}{2}}}{\sqrt{2} C_{D} a g^{\frac{1}{2}}}$

Actually the lagoon is preferably filled, not emptied, during power generation with the water surface rising from zero to $\mathrm{h}$, but this makes no difference to the above equation. Finally, the mean power delivered to the electricity supply during the lagoon recharging process is just the energy stored ((2)) divided by the recharge time $T_{h}$ ((6)). This yields:

$P_{a v}=\frac{C_{D} \rho a h^{\frac{3}{2}} g^{\frac{3}{2}}}{2 \sqrt{2}}$

For the sake of simplicity it has been assumed that a range of hydraulic, electrical and dynamic loss mechanisms, which are generally relatively small, have been ignored [19]. Interestingly while (7) is independent of the lagoon area $(A)$ it is strongly dependent on the head $(h)$ and the outflow cross-section $(a)$.

The dimensional trade-offs intrinsic to lagoon energy storage, which are embedded in (2) and (7), are illustrated in Fig. $6 a$ and 6 b. The former (Fig. 6a) presents stored energy in MWh as a function of depth $h$ for lagoon examples with surface areas ranging from $4.9 \mathrm{~km}^{2}$ to $9.8 \mathrm{~km}^{2}$ to $19.6 \mathrm{~km}^{2}$. The curves clearly emphasise the square law dependence on $\mathrm{h}$ of the energy stored, and 
demonstrate that real gains are available (GWh rather than $\mathrm{MWh}$ ) if depths can be pushed beyond $10 \mathrm{~m}$. This is true even for a modest lagoon occupying an area of $3 \mathrm{~km} \times 3 \mathrm{~km}$. Superimposed on Fig. 6a are six points (black discs) which represent massive storage lagoons, currently either at the planning stage, or in development. These offshore systems are respectively located near Copenhagen 1, Kattegat, Denmark 2, Florida 3, Tamil Nadu, India 4, Manama, Bahrain 5 and Jiangsu, China 6. It is noticeable that planned depths for these projects are modest at $5 \mathrm{~m}$ in Copenhagen and $10 \mathrm{~m}$ in all of the others. The step up in energy storage capacity $(9 \mathrm{GWh})$ projected for Jiangsu has been procured by aiming for a very large jump in its surface area $\left(63 \mathrm{~km}^{2}\right)$ by comparison with the competing systems.

For storage lagoons in the typically $5 \sim 10 \mathrm{~m}$ depth range, Fig. $6 \mathrm{~b}$ provides a good indication of the crosssectional areas (a) of the discharge/recharge valves which will be required to achieve grid level power delivery. For example, one or more apertures exhibiting a combined area of $9 \mathrm{~m}^{2}$ will be needed to extract $2 \mathrm{MW}$ from a $10 \mathrm{~m}$ deep lagoon storage facility.

\subsubsection{Hydraulic piston storage}

Hydroelectric gravitational storage of energy at sea level can also be procured $[14,20,21]$ by employing a weighted piston in a deep water filled shaft (such as a mine shaft), are a larger diameter well or in a much larger area artificial

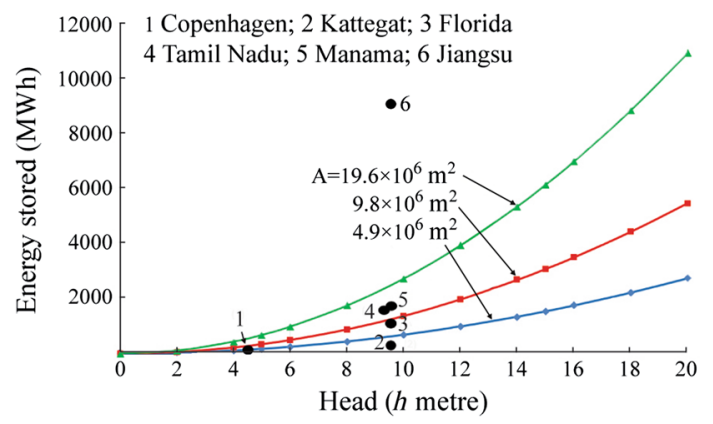

(a) Energy storage capacity as a function of head

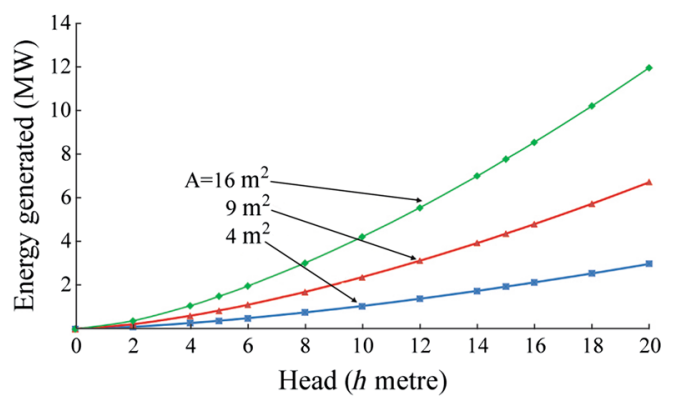

(b) Power delivered as a function of head

Fig. 6 Dimensional trade-offs intrinsic to lagoon energy storage basin, as suggested in Figs. 7a, 7b and 7c. All three of these alternative embodiments are discussed in the literature.

The operational principle of each can be expounded by reference to the deep shaft option in Fig. 7a. This shaft will generally be of circular cross-section and invariant with depth. However, unlike the lagoon alternative (Fig. 5) piston storage achieves the bulk of its gravitational storage, not by shifting water vertically, but by raising a heavier than water piston. This is done by pumping water into the lower cavity of the shaft which is located below the piston (Fig. 7a). This lifting fluid is extracted from the upper chamber via a pump and penstock to the lower one. Fig. 7a depicts the discharging phase of the storage system with the turbine/generator powered by the descending piston at a time of high electricity demand. At low demand the opposite process occurs with electrical power from the grid driving the pump to lift the piston back against gravity to the top of the shaft, whereupon maximum potential energy is stored. For efficient operation of this system, the quality of the pressure seal between the curved surface of the
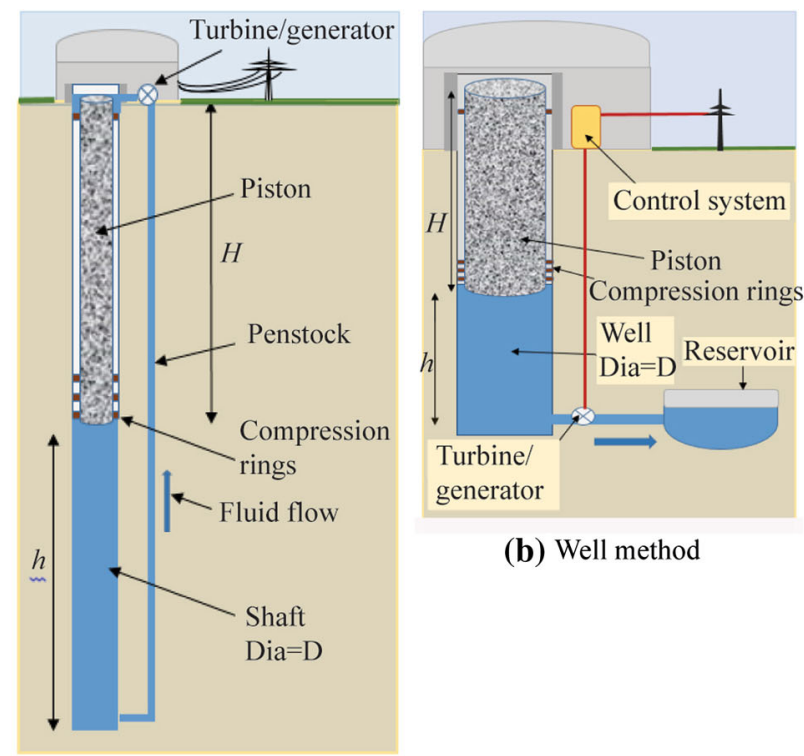

(b) Well method

(a) Deep shaft method

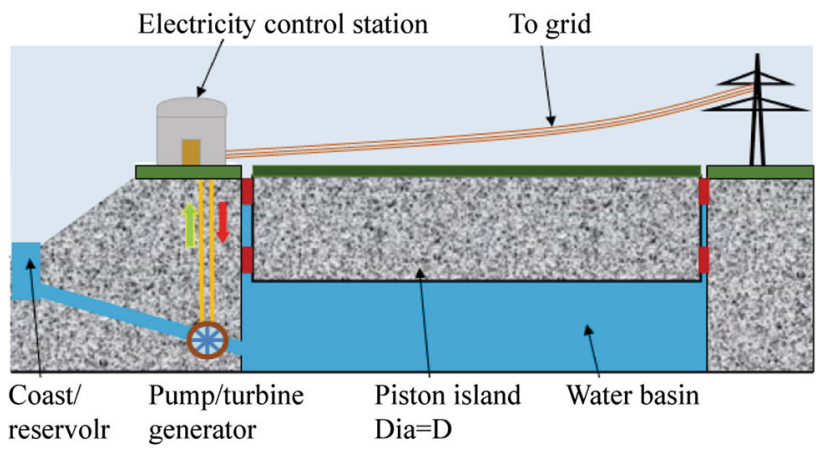

(c) Artificial basin method

Fig. 7 Gravity piston hydroelectric storage schemes 
piston and the lining of the shaft is absolutely key. Arguably, this component is likely to be materially, and mechanically, the main hurdle to successful implementation of the technology.

The well storage concept in Fig. $7 \mathrm{~b}$ and the basin configuration in Fig. 7c operate in a largely similar manner, except that since they are less deep for practical constructional reasons the recharging and discharging of the piston chamber can be implemented less expensively by employing a natural or artificial reservoir.

The relative utility, as storage systems, of these rival arrangements can be reasonably deduced from a simple calculation of energy stored in the piston and in the water column. Referring again to Fig. 7a, if the head of water in the penstock can be assumed to be balanced by water pumped into the upper chamber, it is not unreasonable to assume that the water during the discharge phase is exhausted to a reservoir at base level of the system (as in Fig. 7b and Fig. 7c). In which case we can form the following equation for potential energy stored

$E_{P E}=\frac{\rho A h^{2} g}{2}+\rho_{P} A H h g$

where $\rho\left(\mathrm{kg} / \mathrm{m}^{3}\right)$ is the water density, $\rho_{P}$ is the density of the material forming the piston, $A$ is the cross-sectional area of the well and piston, $H(\mathrm{~m})$ is the piston height and $h(\mathrm{~m})$ is the depth of travel of the piston. To take maximum advantage of the extra weight residing in the piston it should be as large as possible within the given well shaft constraints, without sacrificing vertical movement unduly. The optimum occurs for $H=h$. With this assumption (8) leads to the curves of Fig. 8 for a piston with density $\rho_{P}=2500 \mathrm{~kg} / \mathrm{m}^{3}$ (typical of concrete).

The engineering guidance offered by Fig. 8 to potential developers of hydraulic piston energy storage systems, is that perhaps not unexpectedly, in a single unit, storage levels fall short of 'massive' proportions (GWh's). Nevertheless, significant storage levels in the MWh range are

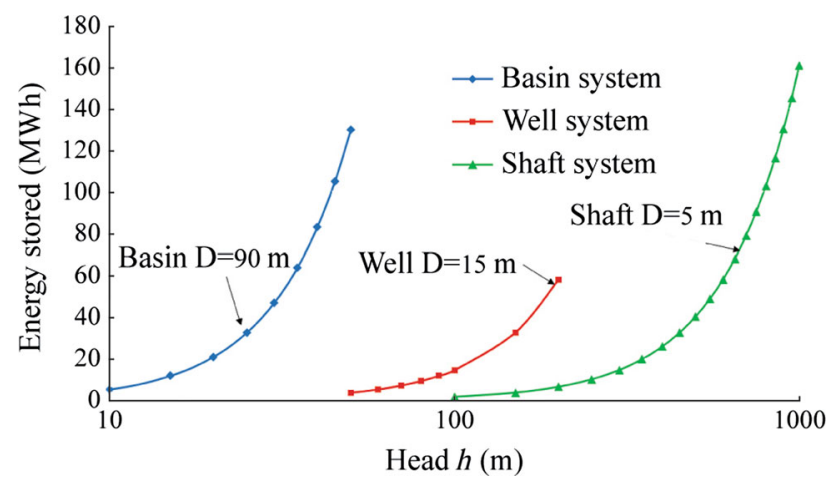

Fig. 8 Energy stored, as a function of head $h$, in piston storage systems available in shaft type systems exhibiting depths approaching $1 \mathrm{~km}$, or in basin configurations of sizeable area (six or more Olympic scale swimming pools). In civil engineering terms the former is practicable only if the shaft diameter is no more than about $5 \mathrm{~m}$, or in the latter case only if the basin depth is less than $20 \mathrm{~m}$. These restriction are primarily related to the fact that any developer seeking, simultaneously, to maximize both depth and width will soon discover that this course rapidly leads to very expensive levels of landscape reshaping. Furthermore, the requirement to seal the gap between the piston and its well by means of compression gaskets of some form, promises to be much easier in narrow lined shafts or in shallow smooth sided basins, than in other possible configurations.

It is perhaps pertinent to note that while a single hydraulic piston unit is unlikely to exceed the $100 \mathrm{MWh}$ capacity, several units, particularly of the shaft geometry, could readily be assembled on a single urban site. Visually it would be no more intrusive than a gas storage complex housing multiple gasometers. Such a site could certainly achieve electrical energy storage levels in excess of $1 \mathrm{GWh}$.

\section{Storage enhanced renewables grid}

From a technological perspective this article has demonstrated that gravitational energy storage in the 'massive' category is feasible by means of sea-level hydro storage (SLHS) techniques. This assertion is supported by simple mathematical models (see section 2) and is confirmed by recent reports, of planned developments and of some progress on prototype systems, in the engineering literature. The accumulating statistical data on sea-level pumped hydro storage configurations suggest that it compares to alternative storage technologies by providing a bridge between rapid charge/discharge low energy systems and the 'massive' capacity systems associated with high altitude pumped hydro. This is summarized in Fig. 3 where SLHS capability, in power versus energy storage terms, is represented by the blue ribbed ellipse extending from $1 \mathrm{MWh}$ to $10^{4} \mathrm{MWh}$ on the energy axis, and from $1 \mathrm{MW}$ to $10^{4} \mathrm{MW}$ on the power axis. This technology arguably fulfils a similar role to flow-battery energy storage (FBES) but without the restriction in instantaneous electrical power delivery which is inherent to batteries.

With this wide range of energy storage techniques (see Fig. 3), which is becoming increasingly available to electrical power grid developers, it is not difficult to envisage possible future trends in electrical grid evolution. These will largely rely on renewable power sources, with back-up from energy storage plants, to mitigate against power fluctuations, power failures, grid instability etc. One 


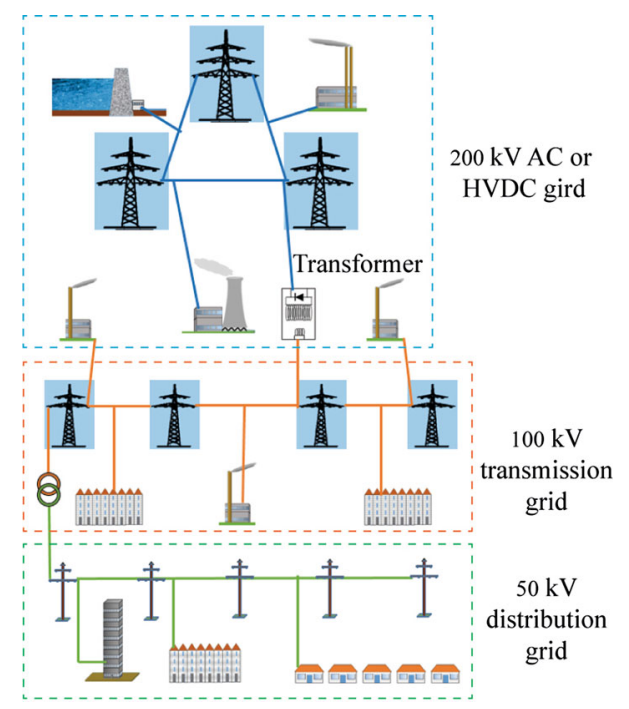

Fig. 9 Schematic of a future Electricity grid system powered by renewable energy sources and backed up by electrical storage plants to 'smooth' power supply fluctuations

possible scheme is suggested in Fig. 9, in which blue connections represent $>200 \mathrm{kV}$ AC or HVDC; orange connections represent $100 \mathrm{kV}$ transmission grid; green connections represent $50 \mathrm{kV}$ distribution grid. The schematic is in three sections as indicated by the caption. The top third represents long distance very high voltage (perhaps DC) operation, powered by hydroelectric stations (dam symbols - top left), by renewables (wind, wave, tidal, solar, bio-fuel, geothermal - all represented by the windturbine icon (top right)) and perhaps nuclear plants (cooling tower icon) during the transition phase. They replace the fossil fuel power stations depicted in Fig. 1. Power quality and continuity of power is predicted to emanate from storage facilities represented by hydro-electric pump storage, hydro-electric lagoon storage, and again nuclear power stations until these can be phased out.

The middle third of the Fig. 9 diagram represents middle distance grid operation at typically $100 \mathrm{kV}$ transformed down from the very high voltage sector as represented by the transformer/control icon. At this voltage, power is again generated by the full range of renewables (wind turbine + solar array icons), again replacing the fossil fuel generators in Fig. 1, while most of the storage facilities listed in Fig. 3 (green battery icons in Fig. 9), could contribute to voltage quality maintenance. Some power distribution to factories and high voltage users is suggested by the factory symbols (see Fig. 1). The lower third of Fig. 9 represents the power distribution network. While some power generation can occur at this level (solar panel symbol), this network mainly provides electrical power to users (as suggested by the administrative tower, factory and housing estate). Voltage smoothing and fault mitigation is secured by employing storage facilities which are matched to the needs of the community being served. These are again represented by the battery icons.

At the distribution level, it is clear that users, from households to hospitals, have very different requirements with respect to the quality, stability and reliability of their electricity supply. This probably means that in addition to the pumped-hydro or compressed air plants capable of delivering significant power levels over long enough time periods to ensure continuity of supply, the distribution grid will also have to incorporate low energy, high discharge rate systems, such as BES, FBES, FES and SMES (see Fig. 3) to guarantee quality. Unfortunately, all of these technologies are intrinsically generators of DC power on discharge. While this may have represented a problem in the past for the AC grid system, recent technology advances in the power supply industries, based on modern power electronics converters, can provide an answer to this mismatch. Developments in flexible AC transmission systems (FACTS) aim to provide robust grid control at times of complex operational demand, usually associated with random external disturbances or fluctuations [22]. FACTS are multi-megawatt proven power electronic devices which are being introduced at the present time into the electricity supply networks. Rather than following conventional practice and switching to stand-by, or base load, fossil fuel powered generators in this power interruption scenario, FACTS enable the maintenance of stability on the grid by permitting storage techniques based on DC devices, such as SMES, FES, BES and CES to be incorporated into grid control systems. Thus by employing storage in conjunction with voltage source converters, it is possible to effectively negate or damp oscillations caused by sudden changes in load conditions [22].

\section{Conclusions}

From a fundamental electrical engineering perspective there is little doubt that an electricity generating and transmission system powered by renewable sources, and backed up by MES facilities, is viable. Recent contributions to the engineering literature attest to this assertion, yet claims that renewables are incompatible with high quality voltage supplies continue, somewhat erroneously, to persist. It is suggested that this is largely attributable to the fact that developments in energy storage lag hugely the growth in renewables.

Generally, in a sustainable electricity supply system, if the renewable power levels available to the grid as a whole are, on average, well in excess of the demand level, then with sufficient storage capacity electricity supplies will be reliable, and capable of meeting quality standards to which 
users have become accustomed. In this article, it is demonstrated that the range and versatility of energy storage methods steadily becoming available to the electrical supply industries, is by no means inconsiderable. Unfortunately, much of it remains at the prototype stage of development. Additionally, a continuing major technology gap exists in the 'massive' energy storage sector, which the paper highlights. It is emphasised that this storage category is essential to the stabilization of any future high voltage transmission grid relying on renewables.

While MES already exists in the form of high altitude pumped storage hydro-electric complexes, these cannot easily be increased in numbers to meet future grid needs, because they are strictly limited by geology and geography, with the best sites largely commandeered. CES is also similarly restricted by geology. This paper argues that a solution potentially lies with lagoon hydro-storage and hydraulic piston storage systems. It is demonstrated that these novel alternatives display power versus energy storage characteristics which very usefully bridge the gap in performance between compact rapid discharge systems including batteries, and storage in high altitude reservoirs. Furthermore, since they are much less dependent on geology and are intrinsically safe, these systems can readily be sited near towns and cities where electricity demand is inevitably at its most acute.

Open Access This article is distributed under the terms of the Creative Commons Attribution 4.0 International License (http:// creativecommons.org/licenses/by/4.0/), which permits unrestricted use, distribution, and reproduction in any medium, provided you give appropriate credit to the original author(s) and the source, provide a link to the Creative Commons license, and indicate if changes were made.

\section{References}

[1] Sanaeepur S, Sanaeepur H, Kargari A et al (2014) Renewable energies: climate-change mitigation and international climate policy. Int J Sustain Energy 33(1):203-212

[2] El-hawari ME (2014) The smart grid: state-of-the-art and future trends. Electr Power Compon Syst 42(3/4):239-250

[3] Hansen J, Kharecha P, Sato K et al (2013) Assessing "dangerous climate change": required reduction of carbon emissions to protect young people, future generations and nature. PLoS One 8(12):e81648

[4] Stocker TF, Qin D, Plattner GK et al (2013) Climate change 2013: the physical science basis. 5th assessment report, intergovernmental panel on climate change (IPCC) Working Group, Bern, Switzerland

[5] Allen MR, Frame DJ, Huntingford C et al (2009) Warming caused by cumulative carbon emissions toward the trillionth tonne. Nature 458:1163-1166
[6] Williams T (2006) Carbon capture and storage: technology, capacity and limitations. PRB05-89E, Library of Parliamentary, Ottawa

[7] Sangster AJ (2014) Engineering the early demise of fossil fuels. Int J Renew Sustain Energy 3(6):115-122

[8] Sangster AJ (2014) Engineering a sustainable and economically active future without fossil fuels. Int $\mathbf{J}$ Eng Trend Technol 17(8):373-380

[9] Boyle G (2007) Renewable electricity and the grid. Earthscan, London

[10] Dell RM, Rand DAJ (2001) Energy storage: a key technology for global energy sustainability. J Power Sources 100(1/2):2-17

[11] Teleke S (2001) Energy storage overview: applications, technologies and economical evaluation. Quanta-Technology LLC, Raleigh

[12] Sangster AJ (2010) Energy for a warming world: a plan to hasten the demise of fossil fuels. Springer, London

[13] Ibrahim H, Ilinca A, Perron J (2008) Energy storage systemscharacteristics and comparisons. Renew Sustain Energy Rev 12(5):1221-1250

[14] Fiske JO (2009) System and method for storing energy. US Patent 8166760B2, 2009-02-04

[15] Chen HS, Cong TN, Yang W et al (2009) Progress in electrical storage system: a critical review. Prog Nat Sci 19(3):291-312

[16] Kondoh J, Ishii I, Yamaguchi H et al (2000) Electrical energy storage systems for energy networks. Energy Convers Manag 41(17): 1863-1874

[17] Paludan G (2009) Green power Island. http://gottliebpaludan. com/en/project/green-power-island

[18] Pool R (2011) Islands with potential. Eng Technol 6(10):67-69

[19] Hamil L (2011) Understanding hydraulics, 3rd edn. Palgrave MacMillan, Basingstoke

[20] Reynolds P (2010) A weighting game. Int Water Power Dam Constr (Online Version), April 13, 2010

[21] Rodrigues EMG, Godina R, Santos SF et al (2014) Energy storage systems supporting increased penetration of renewables in island systems. Energy 75:265-280

[22] Ribeiro PF, Johnson BK, Crow ML et al (2011) Energy storage systems for advanced power applications. Proc IEEE 89(12):1744-1756

[23] Barbier A-C (2003) Emerging energy storage technologies in Europe. Frost \& Sullivan, Tel Aviv

Alan J. SANGSTER Professional development commenced with four years at Ferranti plc, Edinburgh, Scotland, doing research into wide-band travelling wave tubes, and three years with Plessey Radar Ltd., (Seimens) Cowes, U.K., investigating and developing microwave devices and antennas for microwave landing systems and frequency scanned radar systems. In 1972, joined the Heriot-Watt University, Edinburgh-became Professor of Electromagnetic Engineering in 1989. Current research interests lie in the areas of microwave antennas, mm-wave sensing, electrostatically driven micromotors and microactuators, electromagnetic levitation, medical applications of microwaves, microwave and mm-wave electron beam tubes, and the numerical solution of electromagnetic radiation and scattering problems. 